Article

\title{
Reversible Self-Assembly of Backbone-Thermoresponsive Long Chain Hyperbranched Poly(N-Isopropyl Acrylamide)
}

\author{
Ting-Ting Liu ${ }^{1}$, Wei Tian ${ }^{1, *}$, Yan-Li Song ${ }^{1}$, Yang Bai ${ }^{2}$, Peng-Li Wei ${ }^{1}$, Hao Yao ${ }^{1}$ and \\ Hong-Xia Yan ${ }^{1}$ \\ 1 The Key Laboratory of Space Applied Physics and Chemistry, Ministry of Education and Shanxi Key \\ Laboratory of Macromolecular Science and Technology, School of Science, Northwestern Polytechnical \\ University, Xi'an 710072, China; ntt1997@126.com (T.-T.L.); songyanli0514@163.com (Y.-L.S.); \\ yuehe130@126.com (P.-L.W.); yaohao19910901@126.com (H.Y.); hongxiayan@nwpu.edu.cn (H.-X.Y.) \\ 2 Xi'an Mordern Chemistry Research Institute, Xi'an 710065, China; wanan213@126.com \\ * Correspondence: happytw_3000@nwpu.edu.cn; Tel.: +86-029-8843-1565
}

Academic Editor: Jianxun Ding

Received: 10 December 2015; Accepted: 25 January 2016; Published: 28 January 2016

\begin{abstract}
In this paper, we mainly described the reversible self-assembly of a backbone-thermoresponsive, long-chain, hyperbranched poly( $N$-isopropyl acrylamide) (LCHBPNIPAM) in aqueous solution. Here, we revealed a reversible self-assembly behavior of LCHBPNIPAM aqueous solution derived from temperature. By controlling the temperature of LCHBPNIPAM aqueous solution, we tune the morphology of the LCHBPNIPAM self-assemblies. When the solution temperature increased from the room temperature to the lower critical solution temperature of PNIPAM segments, LCHBPNIPAM self-assembled from multi-compartment vesicles into solid micelles. The morphology of LCHBPNIPAM self-assemblies changed from solid micelles to multi-compartment vesicles again when the temperature decreased back to the room temperature. The size presented, at first, an increase, and then a decrease, tendency in the heating-cooling process. The above thermally-triggered self-assembly behavior of LCHBPNIPAM aqueous solution was investigated by dynamic/static light scattering, transmission electron microscopy, atomic force microscopy, fluorescence spectroscopy, ${ }^{1} \mathrm{H}$ nuclear magnetic resonance in $\mathrm{D}_{2} \mathrm{O}$, and attenuated total reflectance Fourier transform infrared spectroscopy. These results indicated that LCHBPNIPAM aqueous solution presents a reversible self-assembly process. The controlled release behaviors of doxorubicin from the vesicles and micelles formed by LCHBPNIPAM further proved the feasibility of these self-assemblies as the stimulus-responsive drug delivery system.
\end{abstract}

Keywords: hyperbranched polymer; reversible self-assembly; poly( $N$-isopropyl acrylamide); thermo-responsiveness; controlled release of drug

\section{Introduction}

Within the last decades, there has been increasing research interest in the various hyperbranched polymers because of their unique chemical and physical properties, such as highly-branched architectures with low viscosity and good solubility, as well as plenty of terminal groups for chemical modifications [1-4]. Particularly, connecting long, linear polymer chains into a hyperbranched structure leads to some unique properties in comparison with traditional hyperbranched polymers, for instance, good mechanical properties in bulk and responsive properties of temperature, $\mathrm{pH}$, and so on. Thus, long-chain hyperbranched polymers (LCHBPs) have potential applications in various fields, such as drug carrier, energy storage, nanotechnology, and catalysis $[5,6]$. 
Up to now, much attention has been paid to the synthesis and properties of LCHBPs. For the synthesis, many step-growth and chain-growth approaches have been invented, which produce a series of LCHBPs such as polystyrene (PSt) [7-10], polyphenylen/es [11] polysiloxanes [12], polyethers [13,14] and so on. The major strategy for the synthesis of LCHBPs is the polycondensation of $\mathrm{AB}_{\mathrm{n}}(n \geqslant 2)$ macromonomers [15-17]. For example, Hutchings et al. reported that long-chain hyperbranched PSt was synthesized by anionic polymerization of a well-defined linear $\mathrm{AB}_{2}$ type PSt macromonomer $[7,10,18]$. Alternatively, the click reaction of alkyne with azide has been proved to be highly efficient $[19,20]$ and has been extensively applied in the synthesis and modification of various polymer materials [21-23]. Pan et al. first utilized alkynyl-azide click reaction to make well-defined hyperbranched PSt by atom transfer radical polymerization (ATRP) of linear $\mathrm{AB}_{2}$ type PSt macromonomer containing an azide group at its one end and two terminal propargyl groups at the other end [24]. Wu et al. [9,15,25,26] obtained a series of long seesaw-type hyperbranched PSt by the click reaction between azide and alkynyl groups of linear $\mathrm{AB}_{2}$ seesaw-type PSt macromonomers which have one alkynyl group in the middle and one azide group at each chain end. For another aspect, studies on the structure-property relationships of LCHBPs have been established [27-34]. It was found that long chain hyperbranched poly(L-lactide)s and polyimides have a significant impact on the rheological properties of such materials in the melt [33].

Until now, however, there are not enough researches that focus on the self-assembly of LCHBPs. Although long chain hyperbranched poly(E-benzyloxycarbonyl-L-lysine) conjugated with thiol-terminated poly(ethylene oxide) could self-assemble into nearly solid micelles in aqueous solution [35], this kind of micelles is hardly able to respond to external stimulus. In another example, Wu et al. [36] studied the thermoresponsive behavior of star-like copolymers with long chain hyperbranched PSt as the core and poly( $N$-isopropyl acrylamide) (PNIPAM) as the grafting chains in aqueous solution. However, the hyperbranched backbone of this star-like copolymer was not responsive to external stimuli and the deeper self-assembly behavior has not been systematically investigated. Furthermore, there are few studies on the reversible self-assembly of LCHBPs. Generally, polymers that undergo a reversible transition between water-soluble and water-insoluble states have been particularly attractive and intensively investigated in recent years, since such a reversible transition generally does not require additional chemical reagents to induce the switch [37]. Therefore, our aim in this study is to regulate the reversible self-assembly process of backbone-thermoresponsive LCHBP in aqueous solution.

In this work, the hyperbranched polymer with long-chain PNIPAM backbone (LCHBPNIPAM) was first synthesized according to our recent work [38]. The thermo-induced reversible self-assembly behavior of LCHBPNIPAM in aqueous solution was then investigated. In the heating-cooling process, the morphology of LCHBPNIPAM self-assemblies can be reversibly regulated from solid multi-compartment vesicles to solid micelles, and back to initial multi-compartment vesicles (Scheme 1a-c). Controlled release results of Doxorubicin (DOX) from LCHBPNIPAM self-assemblies, including multi-compartment vesicles (Scheme 1b-f) and solid micelles (Scheme 1c-g), demonstrated the potential application in the biomedical field.

\section{Materials}

Tris[2-(dimethylamino)ethyl]amine (Me6TREN, 99\%, Alfa Aesar, Shanghai, China), and NIPAM (99\%, Acros, Shanghai, China) were used as received. $N, N, N^{\prime}, N^{\prime \prime}, N^{\prime \prime}$-pentamethyldiethylenetriamine (PMDETA) was supplied by Yutian Chemical, Ltd. (Liyang, China) and used as received without further purification. 4-Dimethylaminopyridine (DMAP, 95\%) was purchased from Sinopharm Chemical Reagent Co., Ltd., Shanghai, China. 8-Anilino-1-naphthalenesulfonic acid ammonium salt hydrate (ANS) and was purchased from Alfa Aesar China. Doxorubicin hydrochloride (DOX. $\mathrm{HCl}$, 99\%) was purchased from Sigma. CuBr was stirred with acetic acid overnight, then washed with ethanol and dried under vacuum at $25{ }^{\circ} \mathrm{C}$. Other reagents were purchased from Tianjin Kermel Chemical Reagents Development Center (Tianjin, China). They were dried with $4 \AA$ A-grade molecular 
sieves before use without further purification. The synthesis of LCHBPNIPAM can be seen in supporting information.

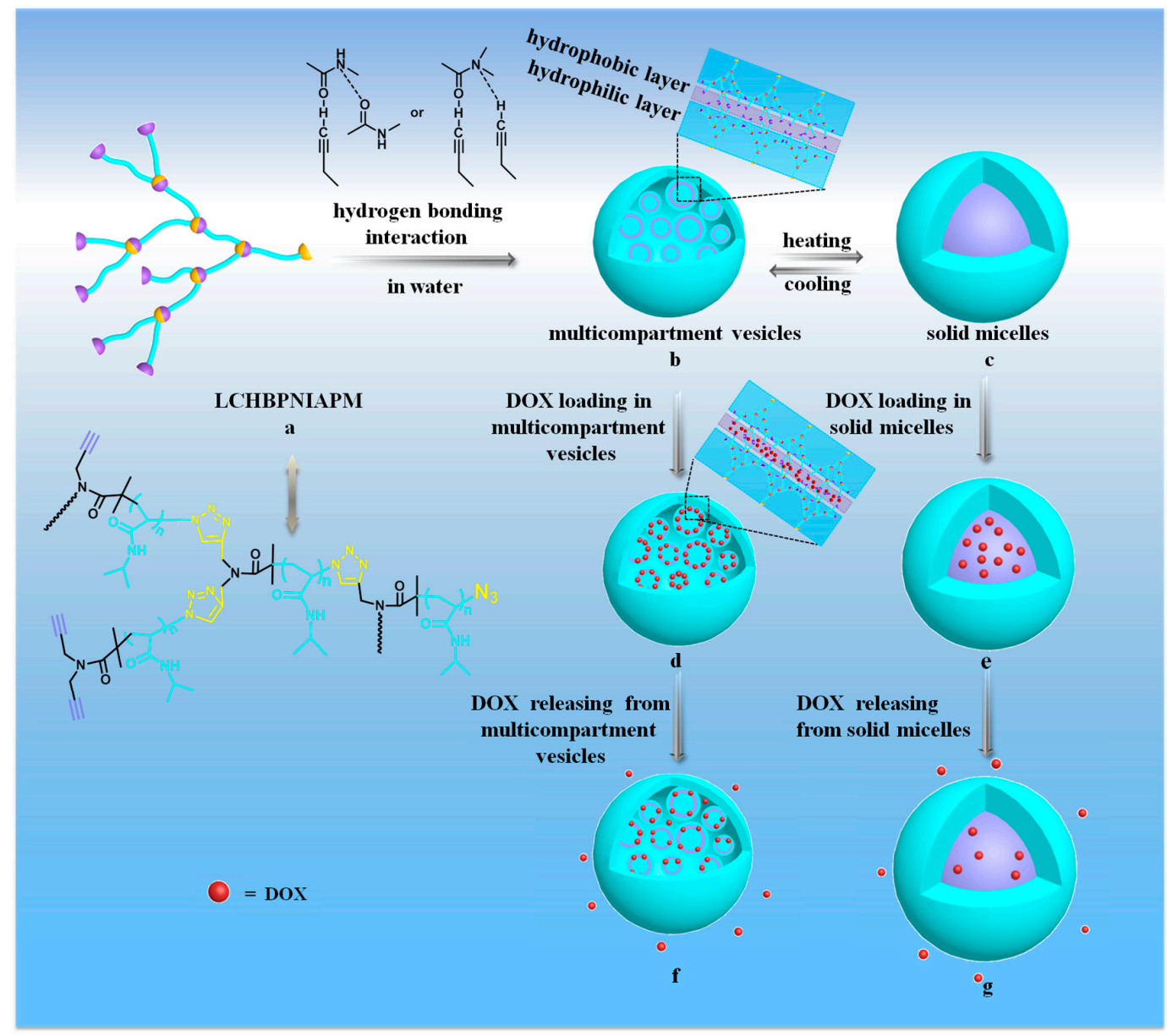

Scheme 1. Schematic representation for the possible self-assembly mechanism of LCHBPNIAPM in aqueous solution at $20{ }^{\circ} \mathrm{C}(\mathbf{a}, \mathbf{b})$ and in the reversible heating-cooling process $(\mathbf{b}, \mathbf{c})$. The release behaviors of DOX from different LCHBPNIAPM self-assemblies; $(\mathbf{b}-\mathbf{f})$ DOX loading in, and releasing from, multi-compartment vesicles at $20^{\circ} \mathrm{C} ;(\mathbf{c}-\mathbf{g})$ DOX loading and releasing from solid micelles at $37^{\circ} \mathrm{C}$.

\section{Characterization Methods}

\subsection{Polymer Solution Characterization}

The size and morphology of the micelles with different polymer concentrations $0.02 \mathrm{mg} / \mathrm{mL}$ were revealed by TEM (Hitachi H-7650, Tokyo, Japan) at an acceleration voltage of $80 \mathrm{kV}$. The samples were prepared according to the literature [39-42]. The polymer solutions were treated at given temperatures for an hour, and $10 \mu \mathrm{L}$ of the self-assembled aggregate solution was then sprayed on a carbon-coated TEM grid (300 mesh). The grid, along with the solution sample, was frozen by placing into liquid nitrogen. The spraying and freezing operation was accomplished in $c a .2 \mathrm{~s}$. The frozen samples were subsequently freeze dried by slow warming to room temperature. The morphology was visualized using an AFM with a tapping mode and a Nanowizard II controller (Benyuan, CSPM 5500, Guangzhou, China). Tip information: radius $\leqslant 33 \mathrm{~mm}$, cantilever length $10 \mu \mathrm{m}$; width $100 \mu \mathrm{m}$; thickness $30 \mathrm{~mm}$, resonant frequency $300 \mathrm{kHz}$, force constant $40 \mathrm{~N} / \mathrm{m}$. A Zetasizer Nano-ZS DLS (Malvern Instruments, Malvern Worcestershire, UK) was used to determine the hydrodynamic diameter of self-assemblies. Each sample was kept at a predetermined temperature for $3 \mathrm{~min}$ before measurement without any 
filter. SLS analysis was performed on a DAWN HELEOS-II multi-angle light scattering detector (Wyatt Technology Corporation, Santa Barbara, CA, USA) operated at $665 \mathrm{~nm}$, using gallium-arsenic as the incident laser beam source. SLS data were collected at six different concentrations of the aggregates and 18 different angles for each concentration. The data were analyzed using the Zimm plot method on HELEOS-II Firmware 2.4.0.4 advanced software to determine $R_{g}$. The emission spectra were recorded by FL (Hitachi F-4600, Tokyo, Japan) from 355 to $550 \mathrm{~nm}$ with an excitation wavelength at $335 \mathrm{~nm}$. The existence of hydrogen bonding in the self-assembly process of the LCHBPs solutions were processed by FTIR-ATR spectra. A solution of the sample in either THF or water was placed in the liquid cell, and the spectra of the solutions were recorded.

\subsection{Polymer Solution Properties}

The LCST of LCHBPNIPAM was determined by Zetasizer Nano-ZS DLS (Malvern Instruments, Malvern Worcestershire, UK). The $D_{z}$ value of LCHBPNIAPM aqueous solutions with a constant polymer concentration of $0.2 \mathrm{mg} / \mathrm{mL}$ were recorded under different temperature conditions. Sample cells were thermostated with an internal constant temperature controller. The temperature ramp was set at $1{ }^{\circ} \mathrm{C} / \mathrm{min}$. The LCST values of the LCHBPNIPAM were defined as the suddenly increasing of $D_{z}$ value during the heating process.

The guest encapsulation of LCHBPNIPAM was measured by FL (Hitachi F-4600, Tokyo, Japan) using ANS $(0.05 \mathrm{mM})$ as guest molecule in a buffer solution with ionic strength equal to $0.1 \mathrm{~mol} / \mathrm{L}$. Typically, the LCHBPNIPAM solution was diluted step-by-step to various desired concentrations (from 0.2 to $2.0 \mathrm{mg} / \mathrm{mL}$ ) using different guest molecule solutions. All solutions were maintained for more than $12 \mathrm{~h}$ to ensure the binding equilibrium and then stirred prior to measurement.

\subsection{Drug Loading and Vitro Release}

The encapsulation and controlled release experiments of DOX were shown as follows. LCHBPNIPAM (20.0 mg) was dissolved in DMF (2.0 mL) and stirred for $2 \mathrm{~h}$. Then DOX. $\mathrm{HCl}(6.0 \mathrm{mg})$ was dissolved in mixture solutions. Then $15 \mu \mathrm{L}$ triethylamine was added dropwise to the solution and the mixture was stirred $12 \mathrm{~h}$ to reach equilibration. The unloaded free drug and the salt produced by neutralization reaction were removed by dialysis using a dialysis tube (cut off $M_{n} 8000-14,000$ ) against $1000 \mathrm{~mL}$ pure water at $20^{\circ} \mathrm{C}$ with $300 \mathrm{r} / \mathrm{min}$ of stirring. Pure water was renewed for six times within $12 \mathrm{~h}$ (every $2 \mathrm{~h}$ ). The final drug loading polymer aqueous had been lyophilized for use. For the release of DOX, the DOX-loaded polymers were dissolved in $5 \mathrm{~mL}$ of phosphate-buffered solutions (PBS) $(1 \mathrm{mg} / \mathrm{mL})$ with different temperature $\left(20\right.$ and $\left.37^{\circ} \mathrm{C}\right)$ and transferred into dialysis bags with a molecular weight cut off of 3500 . Dialysis bags were then put into $30 \mathrm{~mL}$ PBS solutions for release. At given time intervals, $4 \mathrm{~mL}$ of aliquot was taken out to measure the DOX concentration in the dialysate with a UV-VIS spectrophotometer. Additionally, $4 \mathrm{~mL}$ of the corresponding fresh PBS solution was added after each sampling to ensure that the total volume of the buffer solution remained constant. The cumulative release was calculated by using Equation (2) as follows:

$$
\text { Cumulative release }(\%)=\frac{100 \times\left(30.0 C_{n}+4.0 \sum C_{n-1}\right)}{W_{0}}
$$

where $W_{0}(\mathrm{mg})$ is weight of drug in the polymer; $C_{n}(\mathrm{mg} / \mathrm{mL})$ is the concentration of DOX in buffer solution, which was withdrawn for $n$ times, $C_{n-1}(\mathrm{mg} / \mathrm{mL})$ is the concentration of DOX in buffer solution, which was withdrawn for $n-1$ times.

\section{Results and Discussion}

The resulting polymer LCHBPNIPAM $\left(M_{n, S E C-M A L L S}=44,300 \mathrm{Da}, M_{\mathrm{w}} / M_{\mathrm{n}}=1.27 ; \eta_{\mathrm{n}}=7.0\right.$, $\alpha=0.43)$ was obtained by the click chemistry of the $\mathrm{AB}_{2}$ macromonomer $\left(M_{n, S E C-M A L L S}=4200 \mathrm{Da}\right.$, $\left.M_{\mathrm{W}} / M_{\mathrm{n}}=1.20\right)$ according to our previously work [38]. Generally, the backbone-thermoresponsive 
hyperbranched polymer based on hydrophilic-hydrophobic balance can self-assemble to form multi-compartment vesicles below lower critical solution temperature (LCST), and the micelles aggregate to larger particles above LCST [39,43-47]. Thus, the thermo-induced reversible self-assembly behavior of LCHBPNIPAM with an intensely increasing Z-average diameter $\left(D_{z}\right)$ values at $35^{\circ} \mathrm{C}$ (LCST point) (Figure 1B) was easily promoted via directly dissolving it in water with a concentration of $0.2 \mathrm{mg} / \mathrm{mL}$ at a cyclic temperature of heating from 20 to $65{ }^{\circ} \mathrm{C}$, and then cooling to $20{ }^{\circ} \mathrm{C}$. Dynamic/static light scattering (DLS/SLS), transmission electron microscopy (TEM), fluorescence spectrophotometry (FS), and ${ }^{1} \mathrm{H}$ NMR (in $\mathrm{D}_{2} \mathrm{O}$ ) measurements were conducted to obtain deeper insight into the self-assembly morphology and size.
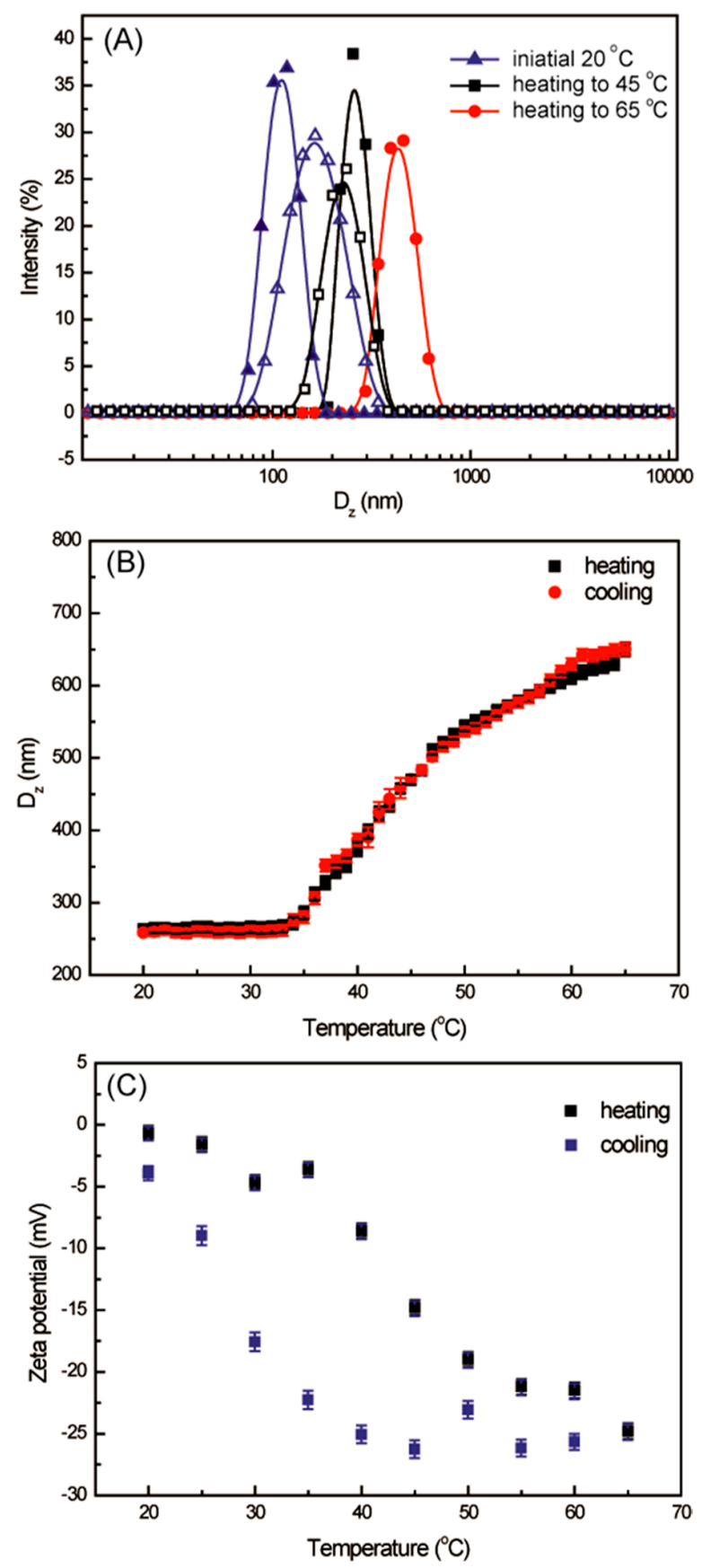

Figure 1. Z-average diameter distributions (A); Z-average diameter values depend on temperature (B) and Zeta-potential (C) of LCHBPNIPAM self-assemblies in aqueous solution $\left(0.2 \mathrm{mg} \cdot \mathrm{mL}^{-1}\right)$ heating from 20 to $65^{\circ} \mathrm{C}$ (solid lines), and then cooling to $20^{\circ} \mathrm{C}$ (dash lines). 
DLS was first used to study the size of LCHBPNIPAM in aqueous solution as shown in Figure 1A,B. It was found that aggregates with a Z-average diameter $\left(D_{Z}\right)$ ranging from 264 to $637 \mathrm{~nm}$ were formed as the temperature was raised from 20 to $65{ }^{\circ} \mathrm{C}$, revealing the occurrence of thermally-induced self-assembly [48]. However, the $D_{Z}$ value came back to $258 \mathrm{~nm}$ as the solution cooling to $20^{\circ} \mathrm{C}$. On the other hand, the change of zeta-potential of LCHBPNIPAM self-assemblies also reflected the reversibility of the self-assembly behaviors (Figure $1 \mathrm{C}$ and Table 1). It was notable that the zeta potential values had a "transition temperature" $\left(c a .35^{\circ} \mathrm{C}\right)$ corresponding to the size transition. The absolute values of Zeta-potential showed an drastic decreasing from -0.64 to $-23.2 \mathrm{mV}$, and then reducing to $-3.58 \mathrm{mV}$, corresponding to the temperature increasing from 20 to $65^{\circ} \mathrm{C}$ and decreasing to $20^{\circ} \mathrm{C}$, respectively. The Figure $1 \mathrm{C}$ shows that the ionization of secondary amine group of PNIPAM chains induced a negative charge in the self-assemblies surface at room temperature. However, the graph clearly demonstrated that the further ionization of the secondary amine group of PNIPAM causes a significant decrease in zeta potential at temperatures above the LCST. The above change tendency was in accordance with the results of size of aggregates [49-52]. One possible reason for the change of zeta potential values $v s$. temperature is that the ionization of secondary amine group of PNIPAM chains is an endothermic process, so increasing the solution temperature may enhance the ionization behavior, further leading to the change of zeta potential as temperature. Additionally, increasing the temperature can promote the coalescence of self-assemblies, and further increase the surface negative charge density of self-assemblies. To further confirm the reversibility of the self-assembly process, we utilized a combination of SLS and DLS techniques to discriminate the inner structure of LCHBPNIPAM self-assemblies at initial and final states, respectively. It is known that the $R_{g} / R_{h}$ value can predict the particle morphology [40]. For example, a solid sphere has an $R_{g} / R_{h}$ value of 0.774 , while a thin-layer hollow sphere of 1.00 . The ratio $R_{g} / R_{h}$ is useful for analyzing the structure of a nano-sized particle, since ratios close to 1.0 indicate that a hollow particle has been formed [40,53]. As shown in Table 1 , the $R_{g} / R_{h}$ values of LCHBPNIPAM self-assemblies were 0.96 and 1.07 at initial and final states, respectively. Therefore, the $R_{g} / R_{h}$ values 0.96 and 1.07 indicated a vesicular structure with a hollow cavity. The $R_{g} / R_{h}$ ratio for the micelles is equal to 1.0. This supports the TEM observation of hollow characteristics. Furthermore, the results of SLS confirmed the reversibility of self-assembly process and the formation of multi-compartment vesicles.

Table 1. Physicochemical parameters of LCHBPNIPAM self-assemblies in aqueous solution $\left(0.2 \mathrm{mg} \cdot \mathrm{mL}^{-1}\right)$.

\begin{tabular}{cccccc}
\hline Temperature $\left({ }^{\circ} \mathbf{C}\right)$ & $\boldsymbol{D}_{a v, T E M}(\mathbf{n m})^{\mathbf{a}}$ & $\boldsymbol{D}_{\boldsymbol{z}} \mathbf{( \mathbf { n m } )}{ }^{\mathbf{b}}$ & PDI $^{\mathbf{c}}$ & Zeta $(\mathbf{m V})^{\mathbf{d}}$ & $\boldsymbol{R}_{\boldsymbol{g}} / \boldsymbol{R}_{\boldsymbol{h}}{ }^{\mathbf{e}}$ \\
\hline 20 & $194 \pm 0.6$ & $264 \pm 0.4$ & 0.504 & $-0.6 \pm 0.3$ & 0.96 \\
45 heating & $345 \pm 0.4$ & $469 \pm 0.5$ & 0.248 & $-14.8 \pm 0.4$ & - \\
65 heating & $540 \pm 0.4$ & $637 \pm 0.3$ & - & $-23.2 \pm 1.2$ & - \\
45 cooling & $301 \pm 0.5$ & $471 \pm 0.4$ & 0.183 & $-26.2 \pm 0.7$ & - \\
20 cooling & $222 \pm 0.6$ & $258 \pm 0.6$ & 0.275 & $-3.6 \pm 0.5$ & 1.07 \\
\hline
\end{tabular}

\footnotetext{
${ }^{a}$ Average diameter determined by TEM; ${ }^{b}$ Z-Average diameter determined by DLS (Repeating three times);

${ }^{\mathrm{c}}$ Polydispersity determined by DLS; ${ }^{\mathrm{d}}$ Zeta-potential determined by DLS; ${ }^{\mathrm{e}}$ Radius of gyration $\left(R_{g}\right)$ determined by SLS and hydrodynamic radius $\left(R_{h}\right)$ determined by DLS.
}

TEM was employed to further demonstrate the size and morphology of LCHBPNIPAM self-assemblies in aqueous solution at different temperatures, as shown in Figure 2. With a freeze-drying process, the intermediate morphologies of the aggregates can be well preserved in this method $[39,41,42,54]$. As can be noticed in Figure 2A-E, the morphologies of self-assemblies changed from multi-compartment vesicles to solid micelles and to multi-compartment vesicles again in accordance with increasing the temperature from 20 to $65^{\circ} \mathrm{C}$ and then decreasing to $20^{\circ} \mathrm{C}$. Being estimated from TEM images, the multi-compartment vesicles had an average diameter $\left(D_{a v}\right)$ of $194 \mathrm{~nm}$ at $20^{\circ} \mathrm{C}$ (Figure $2 \mathrm{~A},(\mathrm{~A}-1)$ ). Gradually, heating to $45^{\circ} \mathrm{C}$ led to an increase of $D_{a v}$ value to $345 \mathrm{~nm}$ (Figure 2B) due to the phase transitions of PNIPAM segments. Moreover, the size of self-assemblies grew to $540 \mathrm{~nm}$ as the 
temperature increasing to $65^{\circ} \mathrm{C}$ (Figure 2C). In order to prove the reversible self-assembly, we made the aqueous solution cooling to 45 and $20^{\circ} \mathrm{C}$, accompanied with the gradually decreasing size of self-assemblies from 540 to $301 \mathrm{~nm}$ at $45^{\circ} \mathrm{C}$, and then $222 \mathrm{~nm}$ at $20^{\circ} \mathrm{C}$ (Figure 2D,E). Moreover, AFM images of the multi-compartment vesicles at $20^{\circ} \mathrm{C}$ (Figure 3) was obtained by tapping-mode AFM for the specimen cast on a mica substrate. Such multi-compartment vesicles confirmed a width of $186 \pm 1.3 \mathrm{~nm}$ (Figure 3), consistent with the width measured by TEM. The layer height was determined to be $103 \pm 3 \mathrm{~nm}$ (Figure 1B). The above change of size of self-assemblies was in accordance with the results of DLS experiments as shown in Table 1.

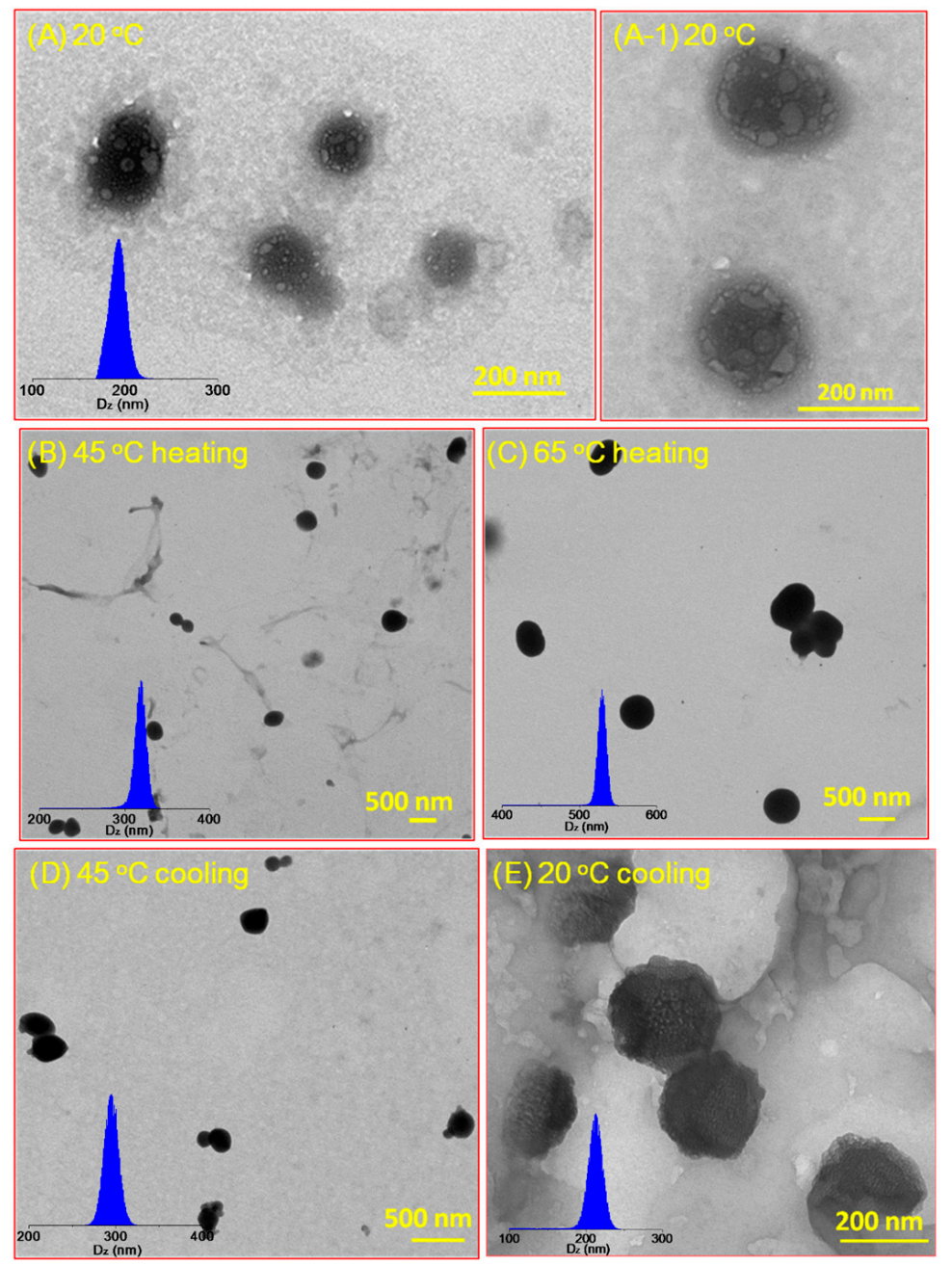

Figure 2. Typical TEM images obtained by drying aqueous solutions of LCHBPNIPAM self-assemblies $(0.2 \mathrm{mg} / \mathrm{mL})$ at $20{ }^{\circ} \mathrm{C}(\mathrm{A}) ; 45^{\circ} \mathrm{C}$ (heating) (B); $65{ }^{\circ} \mathrm{C}$ (heating) $(\mathbf{C}) ; 45^{\circ} \mathrm{C}$ (cooling) (D); and $20{ }^{\circ} \mathrm{C}$ (cooling) (E).

We also explored the inner architecture of LCHBPNIPAM self-assemblies by ${ }^{1} \mathrm{H}$ NMR in $\mathrm{D}_{2} \mathrm{O}$ under different temperatures (Figure 4). It was obvious that all signals of PNIAPM segments were visible at $20^{\circ} \mathrm{C}$ (Figure 4a). However, the proton peaks were weaken with a slight downfield shift after increasing the temperature to $45^{\circ} \mathrm{C}$ (Figure $4 \mathrm{~b}$ ). Moreover, most proton peaks disappeared at $65{ }^{\circ} \mathrm{C}$, revealing that PNIPAM segments collapsed as hydrophobic core layer of LCHBPNIPAM self-assemblies. Furthermore, the signals of PNIPAM chains appeared again along with the solution temperature cooling from 65 to 45 and $20^{\circ} \mathrm{C}$ (Figure $4 \mathrm{~d}$,e). The above results indicated that the self-assembly process of LCHBPNIPAM in aqueous solution was reversible based on the thermoresponsive long-chain PNIPAM backbone. 

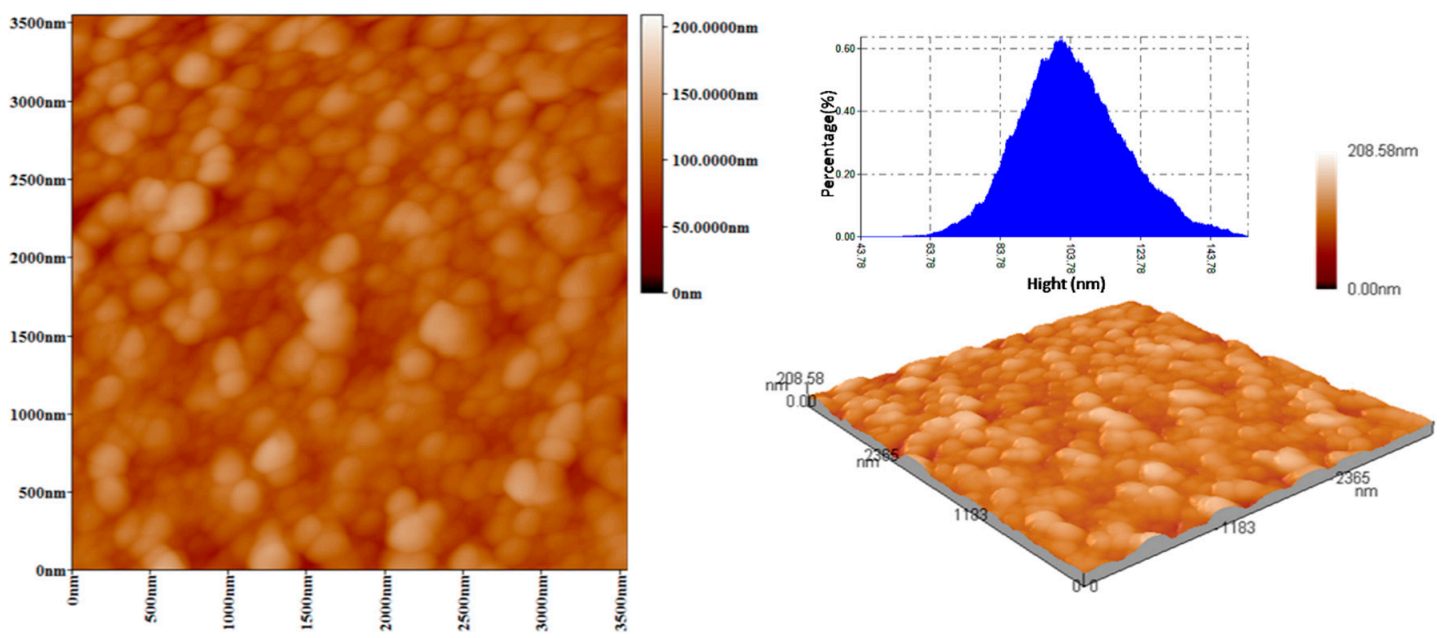

Figure 3. Typical AFM images and its height analysis of LCHBPNIPAM self-assemblies $(0.2 \mathrm{mg} / \mathrm{mL})$ at $20^{\circ} \mathrm{C}$.

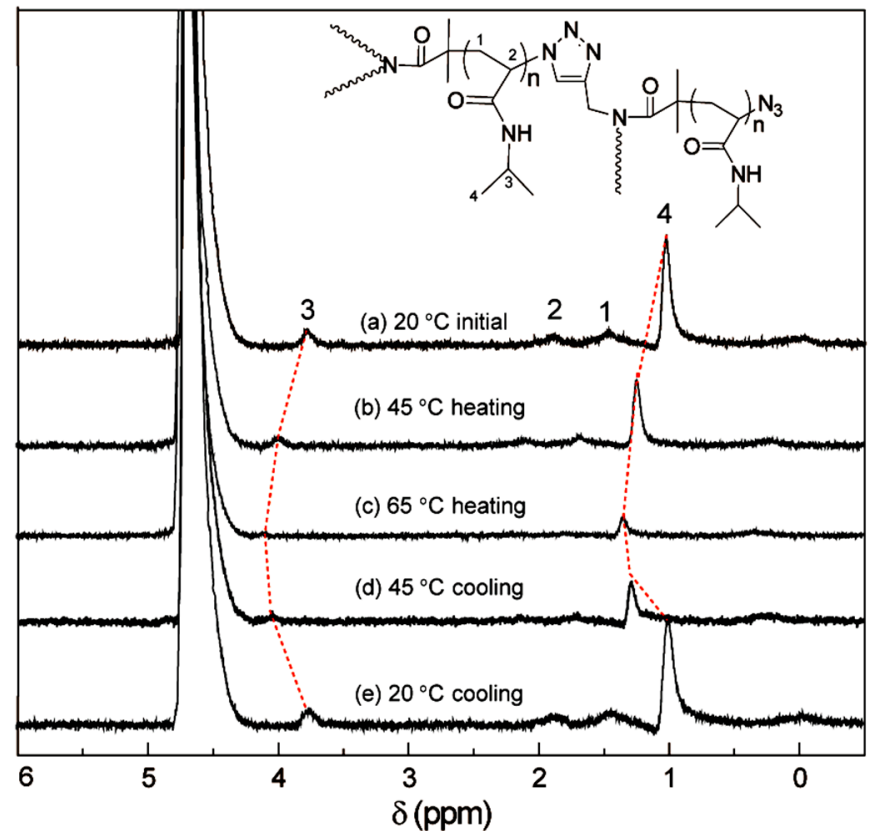

Figure 4. ${ }^{1} \mathrm{H}$ NMR spectra of LCHBPNIPAM self-assemblies in $\mathrm{D}_{2} \mathrm{O}$ at (a) $20^{\circ} \mathrm{C}$; (b) $45^{\circ} \mathrm{C}$ (heating); (c) $60{ }^{\circ} \mathrm{C}$ (heating); (d) $45^{\circ} \mathrm{C}$ (cooling); (e) $20^{\circ} \mathrm{C}$ (cooling).

FS spectroscopy was employed to further confirm the formation, reversibility and encapsulation functionality of LCHBPNIPAM self-assemblies. The critical aggregation concentration (CAC), which acted as a key parameter to quantitatively confirmation whether the micelles had been formed [55], was estimated by FS using pyrene as a hydrophobic probe. The ratio of the intensity of the third and first peaks $\left(I_{3} / I_{1}\right)$ in the emission spectrum was very sensitive to the polarity of the medium surrounding pyrene molecules [56]. The CAC was obtained from the intersection of the baseline and the tangent of the rapidly rising $I_{3} / I_{1}$ curves, indicating the formation of self-assemblies. Thus, the $I_{3} / I_{1}$ value of the pyrene emission spectra versus the logarithm of the LCHBPNIPAM concentration was $0.00675 \mathrm{mg} / \mathrm{mL}$, as shown in Figure 5A. Furthermore, 8-Anilino-1-naphthalenesulfonic acid ammonium salt hydrate (ANS) was selected as the guest molecule because its main absorption peak can be easily detected by FS spectroscopy in an aqueous solution $[57,58]$. Emission spectra of an 
ANS-containing LCHBPNIPAM solution with a concentration of $0.2 \mathrm{mg} / \mathrm{mL}$ was recorded as the solution heating from 20 to $65{ }^{\circ} \mathrm{C}$ and then cooling to $20^{\circ} \mathrm{C}$. As shown in Figure $5 \mathrm{~B}$, a sudden increasing of fluorescence intensity at $\lambda_{\max }=435 \mathrm{~nm}$ from 35 to $55^{\circ} \mathrm{C}$ indicated that the releasing of the 1,8-ANS molecules into aqueous surroundings accompanied with the thermal collapsing of PNIPAM segments [58]. The intensity of ANS-containing solution became the same as the intensity at origin state when the temperature came back to $20^{\circ} \mathrm{C}$, indicating that the micelles came back to original state. Furthermore, the encapsulation function of the formed LCHBPNIPAM self-assemblies was also proved by the FS technique. Figure 5C presented the fluorescence spectra of ANS in the presence of LCHBPNIPAM with various concentrations at $20^{\circ} \mathrm{C}$. It was found that the peak intensities of ANS in LCHBPNIPAM solutions regularly increased with the increase of the LCHBPNIPAM concentration. Figure 5D showed that the emission intensities at the $\lambda_{\max }$ value of ANS increased with increasing LCHBPNIPAM concentration. The above results indicated that ANS guests were encapsulated into LCHBPNIPAM self-assemblies according to our previous work [57,59].
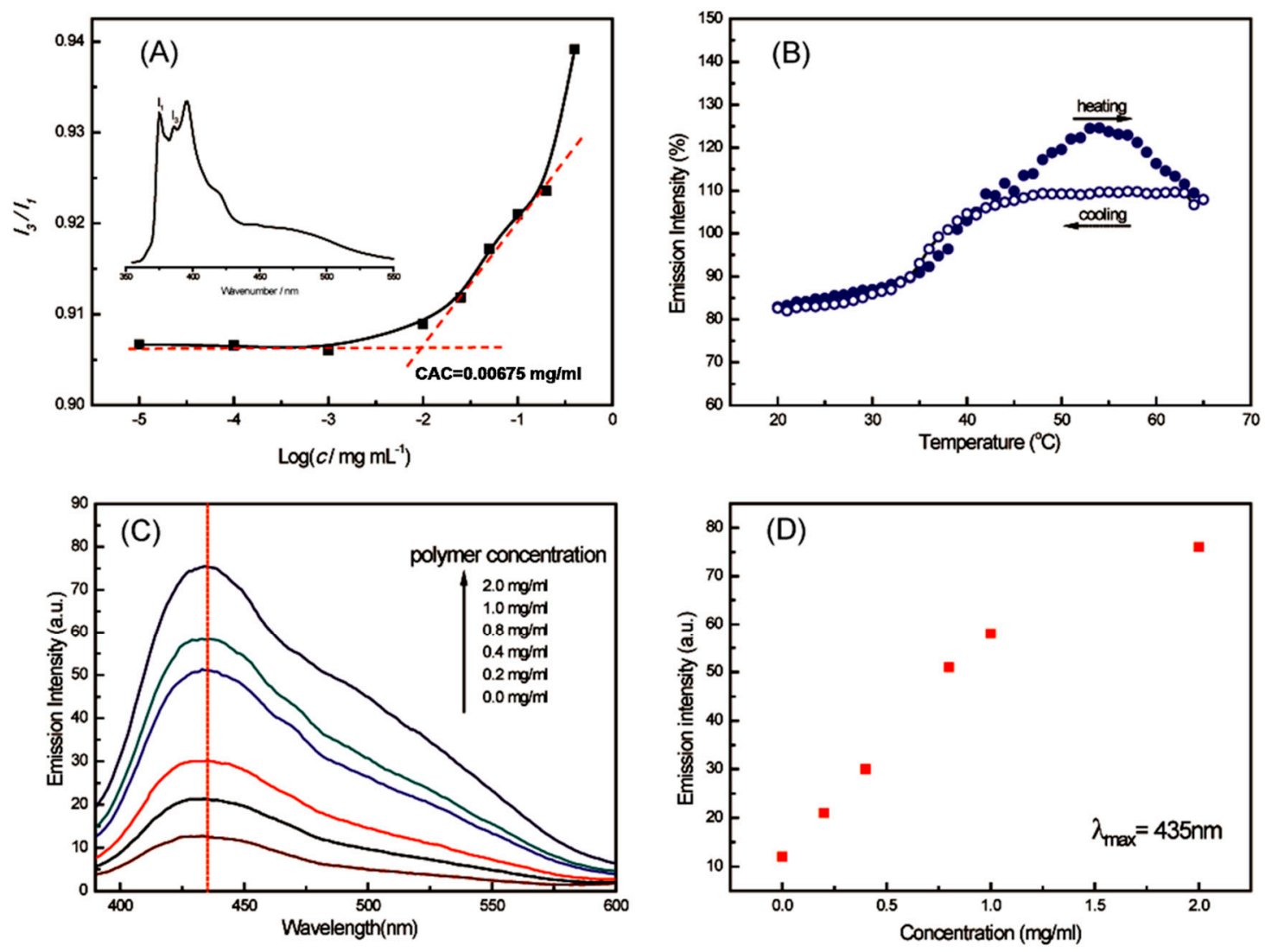

Figure 5. (A) Relationship between the fluorescence intensity ratio $\left(I_{3} / I_{1}\right)$ and LCHBPNIPAM concentration in aqueous solution (Inset: fluorescence emission spectrum of pyrene); (B) maximum values of ANS aqueous solution $\left(0.05 \mathrm{mM}, \lambda_{\max }=435 \mathrm{~nm}\right)$ in the presence of LCHBPNIPAM solution $(0.2 \mathrm{mg} / \mathrm{mL})$ with the gradual elevation and reduction of temperature; (C) fluorescence spectra of ANS in the presence of LCHBPNIPAM with various concentrations at $20^{\circ} \mathrm{C}$; and (D) maximum values of ANS emission intensity at various LCHBPNIPAM concentrations $((A N S)=0.05 \mathrm{mM})$.

These above-mentioned results suggested that the thermo-induced reversible self-assembly of LCHBPNIPAM did, indeed, occur. Herein, the possible self-assembly mechanism was proposed. The hydrophilic PNIPAM segments form multi-compartment vesicles, membrane, and coronas, respectively [60], while the hydrophobic terminal alkynyl groups are located in the center of the multi-compartment vesicle membrane at $20^{\circ} \mathrm{C}$ (Scheme 1a,b). Furthermore, PNIPAM segments collapsed to form solid core above LCST (Scheme 1b,c). On the contrary, the multi-compartment 
vesicles membrane and coronas are formed by PNIPAM segments again corresponding with cooling to $20^{\circ} \mathrm{C}$ (Scheme $1 \mathrm{~b}, \mathrm{c}$ ). In our opinion, active hydrogen existing in the unsaturated triple bonding of the alkynyl group and the amido group of PNIPAM may form intermolecular hydrogen bonding with an oxygen atom and the emergence of hydrogen bonds $\mathrm{CONH} \cdots \mathrm{CON}-$, leading to the formation of different structural self-assemblies.

In order to confirm the existence of hydrogen bonding in the self-assembly process, ATR-FTIR was used in this work. As shown in Figure 6, the ATR-FTIR spectra of LCHBPNIPAM in THF and in $\mathrm{H}_{2} \mathrm{O}$ under different temperatures were compared, one significant change could be seen in the absorbance peak of the $\mathrm{C}=\mathrm{O}$ groups. The peak at about $1646 \mathrm{~cm}^{-1}$ in THF (Figure 6A), shifted to a lower wavenumber of $1644 \mathrm{~cm}^{-1}$ in $\mathrm{H}_{2} \mathrm{O}$ (Figure $6 \mathrm{~B}$ ) at $20^{\circ} \mathrm{C}$, along with the expanding and strengthening of $\mathrm{C}=\mathrm{O}$ absorbance. What is more, the peak further shifted to the wavenumber of $1636 \mathrm{~cm}^{-1}$ with the temperature increasing to $65{ }^{\circ} \mathrm{C}$ (Figure 6B-D). The formation of strong inter/intra-polymer hydrogen bonding might contribute to the above obvious shifting in the LCHBPNIPAM spectra. This result was in agreement with a report on the hydrogen bonding-mediated vesicular self-assembly by Du et al. [53]. It should be noted that the peaks of $C=O$ absorbance came back to $1644 \mathrm{~cm}^{-1}$ as the solution cooling to $20^{\circ} \mathrm{C}$ (Figure $6 \mathrm{E}, \mathrm{F}$ ). Therefore, the inter/intra-polymer hydrogen bonding, indeed, existed in LCHBPNIPAM self-assemblies.

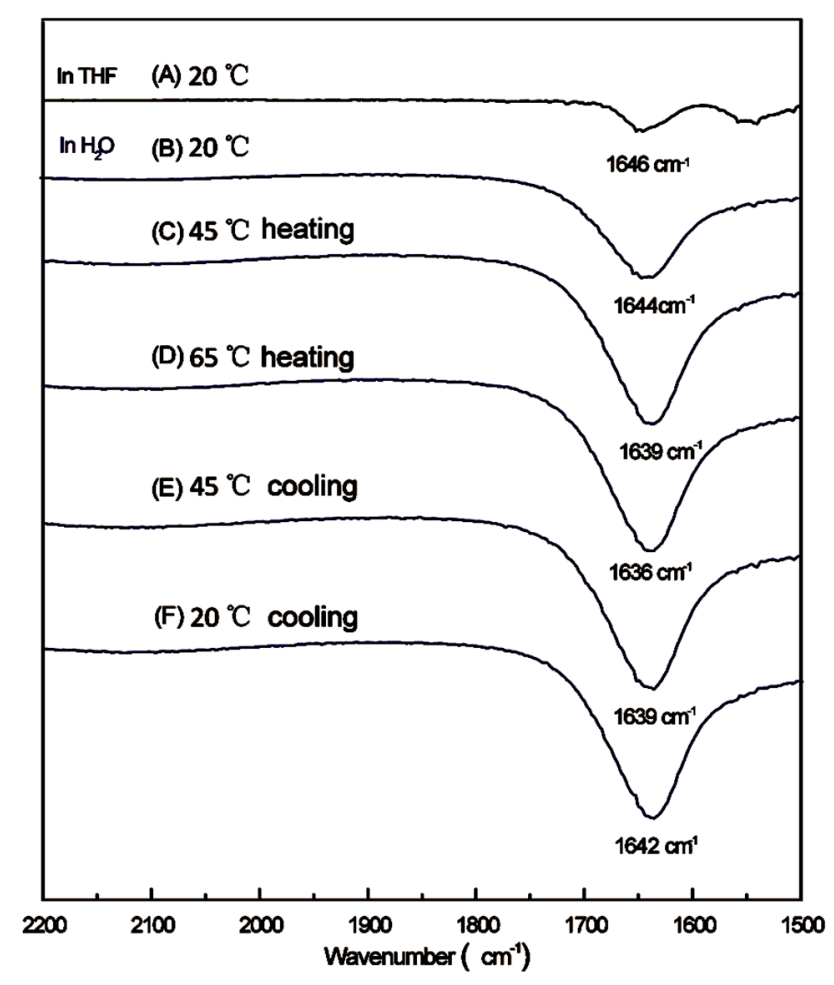

Figure 6. ATR-FTIR spectra of LCHBPNIPAM in THF (A) and in $\mathrm{H}_{2} \mathrm{O}$ at different temperatures (B-F) ((B) $20^{\circ} \mathrm{C}$; (C) $45^{\circ} \mathrm{C}$ (heating); (D) $60^{\circ} \mathrm{C}$ (heating); (E) $45^{\circ} \mathrm{C}$ (cooling); and (F) $20^{\circ} \mathrm{C}$ (cooling)).

The different LCHBPNIPAM self-assemblies, including multi-compartment vesicles (below LCST) and solid micelles (above LCST) could be utilized as a feasible medium for encapsulation and release of drug molecules (Scheme 1). Thus, DOX as a model drug was loaded into the multi-compartment vesicles or micelles for the release experiments. Measurements of DOX release provided a quantitative result of the morphology-controlled DOX release. The release curves of DOX were investigated under different temperature in the solution as shown in Figure 7A. In case of release from system loaded with DOX the release rate at $37{ }^{\circ} \mathrm{C}$ was higher than that of $20^{\circ} \mathrm{C}$, and the maximum amount of release drug is $20 \%$ and $50 \%$ for 20 and $37^{\circ} \mathrm{C}$, respectively. Furthermore, the release mechanism of 
DOX was analyzed with the Higuchi kinetics and the Korsmeyer-Peppas semi-empirical equation (Equation (1)) [61-63]. In the equations, $M_{t} / M_{\infty}$ is the fraction of the drug released at time $t, K$ is a kinetic constant incorporating structural and geometric characteristics of the device, and $\mathrm{n}$ is the release exponent, indicative of the mechanism of drug release. The $n$ value of the Korsmeyer-Peppas model plot under $20^{\circ} \mathrm{C}$ was 0.313 with an $R^{2}$ value of 0.939 and under $37^{\circ} \mathrm{C}$ was 0.325 with an $R^{2}$ value of 0.990 (Figure 7B). This result validated that the release processes were consistent with Fickian diffusion kinetics [60]. The temperature-dependent release of DOX was attributed to the thermosensitive property of PNIPAM segments. As discussed above, the multi-compartment vesicles inhibited the release of DOX at $20^{\circ} \mathrm{C}$. While PNIPAM segments collapsed to form solid core above LCST may result in some crack in the micelles. This could further accelerate the release of encapsulated DOX. Therefore, the DOX release from the loaded self-assemblies further proved the morphology transitions of LCHBPNIPAM self-assemblies below and above LCST.

$$
\frac{M_{t}}{M_{\infty}}=K t^{n}
$$
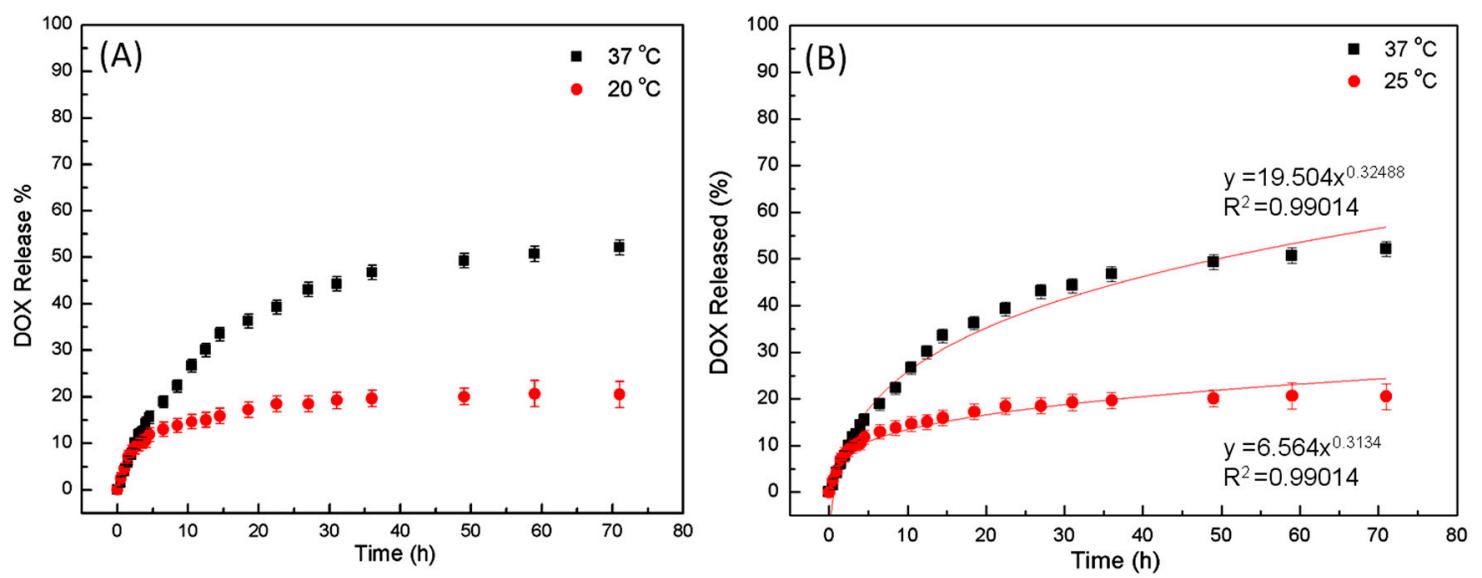

Figure 7. (A) Release profiles of DOX from LCHBPNIPAM self-assemblies as a function of time at $20^{\circ} \mathrm{C}$ (red line) and $37^{\circ} \mathrm{C}$ (black line); and (B) the profile of drug release mechanism based on the Higuchi kinetics and the Korsmeyer-Peppas semi-empirical equation under 20 and $37^{\circ} \mathrm{C}$.

\section{Conclusions}

In conclusion, the introduction of thermoresponsive poly( $N$-isopropyl acrylamide) segments onto long chain hyperbranched polymer (LCHBPNIPAM) backbone can induce a reversible self-assembly. During the heating-cooling process, the morphology of LCHBPNIPAM self-assemblies changed from multi-compartment vesicles to solid micelles and back to multi-compartment vesicles again, and the size underwent a first increase and then decrease. The intermolecular hydrogen bonding plays an important role in forming various self-assembly structures of LCHBPNIPAM at different temperatures. The release rate of Doxorubicin from different LCHBPNIPAM self-assemblies can be effectively controlled. Therefore, these research results may be helpful to extend the application of long-chain hyperbranched polymers in drug delivery system.

Acknowledgments: This work was supported by the National Science Foundation of China (No. 21374088) and Specialized Research Fund for the Doctoral Program of Higher Education of China (20136102110049). Wei Tian thanks the grant from the Program for New Century Excellent Talents of Ministry of Education (NCET-13-0476), the Key Laboratory Program of Science and Technology Coordinator Innovation Project of Shaanxi Province of China (2013SZS17-P01), and the Fundamental Research Funds for the Central Universities (3102015ZY096).

Author Contributions: Wei Tian conceived and designed the experiments; Ting-Ting Liu, Yan-Li Song, Yang Bai, Peng-Li Wei and Hao Yao performed the experiments and analyzed the data; Wei Tian and Ting-Ting Liu wrote the paper; Hong-Xia Yan gave some useful suggestions and revisions. 
Conflicts of Interest: The authors declare no conflict of interest.

\section{References}

1. Voit, B.I.; Lederer, A. Hyperbranched and highly branched polymer architectures-Synthetic strategies and major characterization aspects. Chem. Rev. 2009, 109, 5924-5973. [CrossRef] [PubMed]

2. Gao, C.; Yan, D.Y. Hyperbranched polymers: From synthesis to applications. Prog. Polym. Sci. 2004, 29, 183-275. [CrossRef]

3. Jikei, M.; Kakimoto, M. Hyperbranched polymers: A promising new class of materials. Prog. Polym. Sci. 2001, 26, 1233-1285. [CrossRef]

4. Zhou, Y.F.; Yan, D.Y. Supramolecular self-assembly of amphiphilic hyperbranched polymers at all scales and dimensions: Progress, characteristics and perspectives. Chem. Commun. 2009, 6, 1172-1188. [CrossRef] [PubMed]

5. Pang, Y.; Liu, J.Y.; Wu, J.L.; Li, G.L.; Wang, R.B.; Su, Y.; He, P.; Zhu, X.Y.; Yan, D.Y.; Zhu, B.S. Synthesis, characterization, and in vitro evaluation of long-chain hyperbranched poly(ethylene glycol) as drug carrier. Bioconj. Chem. 2010, 21, 2093-2102. [CrossRef] [PubMed]

6. Konkolewicz, D.; Monteiro, J.M.; Perrier, S. Dendritic and hyperbranched polymers from macromolecular units: Elegant approaches to the synthesis of functional polymers. Macromolecules 2011, 44, 7076-7087. [CrossRef]

7. Hutchings, L.R.; Roberts-Bleming, S.J. DendriMacs. Well-defined dendritically branched polymers synthesized by an iterative convergent strategy involving the coupling reaction of $\mathrm{AB}_{2}$ macromonomers. Macromolecules 2006, 39, 2144-2152. [CrossRef]

8. Konkolewicz, D.; Gray-Weale, A.; Perrier, S. Hyperbranched polymers by thiol-yne chemistry: From small molecules to functional polymers. J. Am. Chem. Soc. 2009, 131, 18075-18077. [CrossRef] [PubMed]

9. He, C.; He, W.D.; Li, L.W.; Jiang, W.X.; Tao, J.; Yang, J.; Chen, L.; Ge, X.S.; Chen, S.Q. Controlling the formation of long-subchain hyperbranched polystyrene from seesaw-type $\mathrm{AB}_{2}$ macromonomers: Solvent polarity and solubility. J. Polym. Sci. A Polym. Chem. 2012, 50, 3214-3224. [CrossRef]

10. Hutchings, L.R.; Dodds, J.M.; Roberts-Bleming, S.J. HyperMacs. Long chain branched analogues of hyperbranched polymers prepared by the polycondensation of $\mathrm{AB}_{2}$ macromonomers. Macromol. Symp. 2006, 240, 56-67. [CrossRef]

11. Xie, C.; Ju, Z.H.; Zhang, C.; Yang, Y.L.; He, J.P. Dendritic block and dendritic brush copolymers through anionic macroinimer approach. Macromolecules 2013, 46, 1437-1446. [CrossRef]

12. Zheng, Y.; Thurecht, K.J.; Wang, W.X. Polysiloxanes Polymers with hyperbranched structure and multivinyl functionality. J. Polym. Sci. A Polym. Chem. 2012, 50, 629-637. [CrossRef]

13. Jiang, W.X.; He, W.D.; He, C. Synthesis of long-subchain hyperbranched PCL through SCV-ATRP of macroinimers with (meth)acrlate group. J. Polym. Sci. A Polym. Chem. 2012, 50, 3475-3480. [CrossRef]

14. Malmstrom, E.; Johansson, M.; Hult, A. The effect of terminal alkyl chains on hyperbranched polyesters based on 2,2-bis (hydroxymethyl) propionic acid. Macromol. Chem. Phys. 1996, 197, 3199-3207. [CrossRef]

15. Li, L.W.; Zhou, J.F.; Wu, C. Intrachain folding and interchain association of hyperbranched chains with long uniform subchains made of amphiphilic diblock copolymers. Macromolecules 2012, 45, 9391-9399. [CrossRef]

16. Jikei, M.; Suzuki, M.; Itoh, K.; Matsumoto, K.; Saito, Y.; Kawaguchi, S. Synthesis of hyperbranched poly(L-lactide)s by self-polycondensation of $\mathrm{AB}_{2}$ macromonomers and their structural characterization by light scattering measurements. Macromolecules 2012, 45, 8237-8244. [CrossRef]

17. Mishra, K.; Joy, A. Dual functionalized telechelic block copolymers with reproducible block sizes prepared by microwave assisted RAFT polymerization. Polymer 2015, 66, 110-121. [CrossRef]

18. Hutchings, L.R.; Dodds, J.M.; Roberts-Bleming, S.J. HyperMacs: Highly branched polymers prepared by the polycondensation of $\mathrm{AB}_{2}$ macromonomers, synthesis and characterization. Macromolecules 2005, 38, 5970-5980. [CrossRef]

19. Kolb, H.C.; Finn, M.G.; Sharpless, K.B. Click-Chemie: Diverse chemische Funktionalität mit einer Handvoll guter Reaktionen. Angew. Chem. Int. Ed. 2001, 40, 2004-2021. [CrossRef]

20. Binder, W.H.; Sachsenhofer, R. "Click” chemistry in polymer and materials science. Macromol. Rapid Commun. 2007, 28, 15-54. [CrossRef] 
21. Whittaker, M.R.; Urbani, C.N.; Monteiro, M.J. Synthesis of 3-miktoarm stars and 1st generation mikto dendritic copolymers by "living" radical polymerization and "click" chemistry. J. Am. Chem. Soc. 2006, 128, 11360-11361. [CrossRef] [PubMed]

22. Gao, H.F.; Matyjaszewski, K. Synthesis of star polymers by a combination of ATRP and the "Click" coupling method. Macromolecules 2006, 39, 4960-4965. [CrossRef]

23. Englert, B.C.; Bakbak, S.; Bunz, U.H.F. Click chemistry as a powerful tool for the construction of functional Poly( $p$-phenyleneethynylene)s: Comparison of pre- and post-functionalization schemes. Macromolecules 2005, 38, 5868-5877. [CrossRef]

24. Li, Z.K.; Sun, M.; Qiao, H.M.; Pan, C.Y. Synthesis and characterization of hyperbranched polystyrene via click reaction of $\mathrm{AB}_{2}$ macromonomer. J. Polym. Sci. A Polym. Chem. 2010, 48, 454-462.

25. Li, L.W.; He, C.; He, W.; Wu, C. Formation kinetics and scaling of "defect-free" hyperbranched polystyrene chains with uniform subchains prepared from seesaw-type macromonomers. Macromolecules 2011, 44, 8195-8206. [CrossRef]

26. He, C.; Li, L.W.; He, W.D.; Jiang, W.X.; Wu, C. “Click” long seesaw-type A B A Chains together into huge defect-free hyperbranched polymer chains with uniform subchains. Macromolecules 2011, 44, 6233-6236. [CrossRef]

27. Cao, K.; Li, Y.; Lu, Z.Q.; Wu, S.L.; Chen, Z.H.; Yao, Z.; Huang, Z.M. Preparation and characterization of high melt strength polypropylene with long chain branched structure by the reactive extrusion process. J. Appl. Polym. Sci. 2011, 121, 3384-3392. [CrossRef]

28. Yao, Z.; Lu, Z.Q.; Zhao, X.; Qu, B.W.; Shen, Z.C.; Cao, K. Synthesis and characterization of high-density polypropylene-grafted polyethylene via a macromolecular reaction and its rheological behavior. J. Appl. Polym. Sci. 2009, 111, 2553-2561. [CrossRef]

29. Dodds, J.M.; Luca, E.D.; Hutchings, L.R.; Clarke, N. Rheological properties of HyperMacs-long-chain branched analogues of hyperbranched polymers. J. Appl. Polym. Sci. B Polym. Phys. 2007, 45, 2762-2769. [CrossRef]

30. Sugimoto, M.; Koizumi, T.; Taniguchi, T.; Koyama, K.; Saito, K.; Nonokawa, D.; Morita, T. Melt rheology of hyperbranched-polystyrene synthesized with multisite macromonomer. J. Appl. Polym. Sci. B Polym. Phys. 2009, 47, 2226-2237. [CrossRef]

31. Clarke, N.; Luca, E.D.; Dodds, J.M.; Kimani, S.M.; Hutchings, L.R. HyperMacs—Long chain hyperbranched polymers: A dramatically improved synthesis and qualitative rheological analysis. Eur. Polym. J. 2008, 44, 665-676. [CrossRef]

32. Lu, Y.Y.; An, L.J.; Wang, Z.G. Intrinsic viscosity of polymers: General theory based on a partially permeable sphere model. Macromolecules 2013, 46, 5731-5740. [CrossRef]

33. Wang, L.Y.; Jing, X.B.; Cheng, H.B.; Hu, X.L.; Yang, L.X.; Huang, Y.B. Blends of linear and long-chain branched poly(L-lactide)s with high melt strength and fast crystallization rate. Ind. Eng. Chem. Res. 2012, 51, 10088-10099. [CrossRef]

34. Li, L.W.; Lu, Y.Y.; An, L.J.; Wu, C. Experimental and theoretical studies of scaling of sizes and intrinsic viscosity of hyperbranched chains in good solvents. J. Chem. Phys. 2013, 138, 114908. [CrossRef] [PubMed]

35. Chang, X.; Dong, C.M. Synthesis of hyperbranched polypeptide and PEO block copolymer by consecutive thiol-yne chemistry. Biomacromolecules 2013, 14, 3329-3337. [CrossRef] [PubMed]

36. He, C.; Jin, B.K.; He, W.D.; Ge, X.S.; Tao, J.; Yang, J.; Chen, S.Q. Solvent replacement to thermo-responsive nanoparticles from long-subchain hyperbranched PSt grafted with PNIPAM for encapsulation. J. Polym. Sci. A Polym. Chem. 2013, 51, 2142-2149. [CrossRef]

37. Wang, Y.C.; Tang, L.Y.; Li, Y.; Wang, J. Thermoresponsive block copolymers of poly(ethylene glycol) and polyphosphoester: Thermo-induced self-assembly, biocompatibility, and hydrolytic degradation. Biomacromolecules 2009, 10, 66-73. [CrossRef] [PubMed]

38. Liu, T.T.; Tian, W.; Zhu, Y.Q.; Bai, Y.; Yan, H.X.; Du, J.Z. How does a tiny terminal alkynyl end group drive fully hydrophilic homopolymers to self-assemble into vesicles and flower-like complex particles? Polym. Chem. 2014, 5, 5077-5088. [CrossRef]

39. Fan, W.W.; Fan, X.D.; Tian, W.; Zhang, X.; Wang, G.; Zhang, W.B.; Bai, Y.; Zhu, X.Z. Phase transition dynamics and mechanism for backbone-thermoresponsive hyperbranched polyethers. Polym. Chem. 2014, 5, 4022-4031. [CrossRef] 
40. Duan, H.W.; Chen, D.Y.; Jiang, M.; Gan, W.J.; Li, S.J.; Wang, M.; Gong, J. Self-assembly of unlike homopolymers into hollow spheres in nonselective solvent. J. Am. Chem. Soc. 2001, 123, 12097-12098. [CrossRef] [PubMed]

41. Burke, S.E.; Eisenberg, A. Kinetics and mechanisms of the sphere-to-rod and rod-to-sphere transitions in the ternary system PS310-b-PAA52/dioxane/water. Langmuir 2001, 17, 6705-6714. [CrossRef]

42. Chen, L.; Shen, H.W.; Eisenberg, A. Kinetics and mechanism of the rod-to-vesicle transition of block copolymer aggregates in dilute solution. J. Phys. Chem. B 1999, 103, 9488-9497. [CrossRef]

43. Liu, J.Y.; Huang, W.; Pang, Y.; Huang, P.; Zhu, X.Y.; Zhou, Y.F.; Yan, D.Y. Molecular self-assembly of a homopolymer: An alternative to fabricate drug-delivery platforms for cancer therapy. Angew. Chem. Int. Ed. 2011, 50, 9162-9166. [CrossRef] [PubMed]

44. Jin, Y.; Song, L.; Wang, D.L.; Qiu, F.; Yan, D.Y.; Zhu, B.S.; Zhu, X.Y. Synthesis and self-assembly of nonamphiphilic hyperbranched polyoximes. Soft Matter 2012, 8, 10017-10025. [CrossRef]

45. Liu, J.Y.; Pang, Y.; Chen, J.; Huang, P.; Huang, W.; Zhu, X.Y.; Yan, D.Y. Hyperbranched polydiselenide as a self assembling broad spectrum anticancer agent. Biomaterials 2012, 33, 7765-7774. [CrossRef] [PubMed]

46. Xia, Y.M.; Wang, Y.M.; Wang, Y.P.; Wang, D.L.; Deng, H.P.; Zhuang, Y.Y.; Yan, D.Y.; Zhu, B.S.; Zhu, X.Y. Backbone-thermoresponsive hyperbranched polyglycerol by random copolymerization of glycidol and 3-methyl-3-(hydroxymethyl)oxetane. Macromol. Chem. Phys. 2011, 212, 1056-1062. [CrossRef]

47. Zhou, Y.F.; Yan, D.Y.; Dong, W.Y.; Tian, Y. Temperature-responsive phase transition of polymer vesicles: Real-time morphology observation and molecular mechanism. J. Phys. Chem. B 2007, 111, 1262-1270. [CrossRef] [PubMed]

48. Wang, H.N.; Sun, S.T.; Wu, P.Y. Thermodynamics of hyperbranched poly(ethylenimine) with isobutyramide residues during phase transition: An insight into the molecular mechanism. J. Phys. Chem. B 2011, 115, 8832-8844. [CrossRef] [PubMed]

49. Sun, S.T.; Zhang, W.D.; Zhang, W.; Wu, P.Y.; Zhu, X.L. Dynamic self-aggregation behavior of a PNIPAM-based nonlinear multihydrophilic block copolymer revealed by two-dimensional correlation spectroscopy. Soft Matter 2012, 8, 3980-3987. [CrossRef]

50. Sun, S.T.; Wu, P.Y.; Zhang, W.D.; Zhang, W.; Zhu, X.L. Effect of structural constraint on dynamic self-assembly behavior of PNIPAM-based nonlinear multihydrophilic block copolymers. Soft Matter 2013, 9, 1807-1816. [CrossRef]

51. Naha, P.C.; Bhattacharya, K.; Tenuta, T.; Dawsonc, A.K.; Lynch, I.; Gracia, A.; Lyng, M.F.; Byrne, J.H. Intracellular localisation, geno- and cytotoxic response of polyN-isopropylacrylamide (PNIPAM) nanoparticles to human keratinocyte (HaCaT) and colon cells (SW 480). Toxicol. Lett. 2010, 198, 134-143. [CrossRef] [PubMed]

52. Burdukova, E.; Li, H.; Bradshaw, D.; Franks, G. Poly(N-isopropylacrylamide) (PNIPAM) as a flotation collector: Effect of temperature and molecular weight. Miner. Eng. 2010, 23, 921-927. [CrossRef]

53. Zhu, Y.Q.; Liu, L.; Du, J.Z. Probing into homopolymer self-assembly: How does hydrogen bonding influence morphology? Macromolecules 2013, 46, 194-203. [CrossRef]

54. Zhou, Y.F.; Huang, W.; Liu, J.Y.; Zhu, X.Y.; Yan, D.Y. Self-assembly of hyperbranched polymers and its biomedical applications. Adv. Mater. 2010, 22, 4567-4590. [CrossRef] [PubMed]

55. Astafieva, I.; Zhong, X.F.; Eisenberg, A. Critical micellization phenomena in block polyelectrolyte solutions. Macromolecules 1993, 26, 7339-7352. [CrossRef]

56. Ohashi, H.; Hiraoka, Y.; Yamaguchi, T. An autonomous phase transition-complexation/decomplexation polymer system with a molecular recognition property. Macromolecules 2006, 39, 2614-2620. [CrossRef]

57. Liu, Y.Y.; Zhong, Y.B.; Nan, J.K.; Tian, W. Star polymers with both temperature sensitivity and inclusion functionalities. Macromolecules 2010, 43, 10221-10230. [CrossRef]

58. Karjalainen, E.; Chenna, N.; Laurinmäki, P.; Butcher, S.J.; Tenhu, H. Diblock copolymers consisting of a polymerized ionic liquid and poly( $N$-isopropylacrylamide). Effects of PNIPAM block length and counter ion on self-assembling and thermal properties. Polym. Chem. 2013, 4, 1014-1024. [CrossRef]

59. Tian, W.; Wei, X.Y.; Liu, Y.Y.; Fan, X.D. A branching point thermo and pH dual-responsive hyperbranched polymer based on poly ( $N$-vinylcaprolactam) and poly ( $N, N$-diethyl aminoethyl methacrylate). Polym. Chem. 2013, 4, 2850-2863. [CrossRef]

60. Fan, L.; Lu, H.; Zou, K.D.; Chen, J.; Du, J.Z. Homopolymer vesicles with a gradient bilayer membrane as drug carriers. Chem. Commun. 2013, 49, 11521-11523. [CrossRef] 
61. Nie, S.F.; Hsiao, W.; Pan, W.S.; Yang, Z.J. Thermoreversible Pluronic ${ }^{\circledR}$ F127-based hydrogel containing liposomes for the controlled delivery of paclitaxel: In vitro drug release, cell cytotoxicity, and uptake studies. Int. J. Nanomed. 2011, 6, 151-166.

62. Peppas, N.A.; Sahlin, J.J. A simple equation for the description of solute release. III. Coupling of diffusion and relaxation. Int. J. Pharm. 1989, 57, 169-172.

63. Siepmann, J.; Peppas, N.A. Modeling of drug release from delivery systems based on hydroxypropyl methylcellulose (HPMC). Adv. Drug Deliv. Rev. 2011, 48, 139-157. [CrossRef]

(C) 2016 by the authors; licensee MDPI, Basel, Switzerland. This article is an open access article distributed under the terms and conditions of the Creative Commons by Attribution (CC-BY) license (http://creativecommons.org/licenses/by/4.0/). 